\title{
Magnetic Electrospun Fibers for Cancer Therapy
}

\author{
Chaobo Huang, Stefaan J. Soenen, Joanna Rejman, Jesse Trekker, Liu Chengxun, \\ Liesbet Lagae, Wim Ceelen, Claire Wilhelm, Jo Demeester, and Stefaan C. De Smedt**
}

Iron oxide nanoparticles (IONPs) for magnetic hyperthermia in cancer treatment have recently gained substantial interest. Unfortunately, the use of free IONPs still faces major challenges such as poor tumor targetability, high variability in the amount of IONPs taken up by the tumor and the IONP leakage from dead cancer cells into the surrounding healthy tissues. The present work reports on electrospun fiber webs, heavily loaded with $50 \mathrm{~nm}$ sized IONPs. The high loading capacity of the fibers enables significant heating of the environment upon applying an alternating magnetic field. Furthermore, magnetic fibers can be repeatedly heated without loss of heating capacity or release of IONPs. Upon functionalization of the fiber surface with collagen, human SKOV-3 ovarian cancer cells attached well to the fibers. Applying an alternating magnetic field during $\mathbf{1 0}$ minutes to the fiber webs killed all fiber-associated cancer cells. Killing the cells using this method seemed more efficient compared to the use of a warm water bath. As the fiber webs can be i) loaded with a well-controlled amount of IONPs and ii) localized in the body by Magnetic Resonance Imaging, magnetic electrospun fibers may become promising materials for a highly reproducible (repeated) heating of cancer tissues in vivo.

\section{Introduction}

Cancer is a leading cause of death, often caused by the transformation of a normal cell into a tumor cell through a multistage process. Over the past decade, a better molecular profiling of tumors has improved our general knowledge about cancer and provided new ways of treating them. ${ }^{[1]}$ Unfortunately, the high

\footnotetext{
C. Huang, Dr. S. J. Soenen, Dr. J. Rejman, Prof. J. Demeester, Prof. S. C. De Smedt Lab of General Biochemistry and Physical Pharmacy Faculty of Pharmacy

Ghent University

Harelbekestraat 72, B9000 Ghent, Belgium

E-mail: stefaan.desmedt@ugent.be

J. Trekker, L. Chengxun, Dr. L. Lagae

imec, Kapeldreef 75, B3001 Leuven, Belgium

Dr. W. Ceelen

Department of Surgery

Ghent University Hospital

De Pintelaan 185, B9000 Ghent, Belgium

Dr. C. Wilhelm

Laboratoire Matière et Systèmes Complexes

University Paris-Diderot

Paris Cedex 13, 75205 Paris, France
}

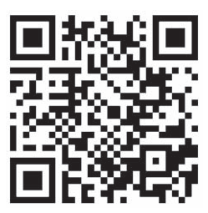

DOI: 10.1002/adfm.201102171 complexity of cancer and the wide variations in different cancer types have thus far made it impossible to find an optimal and generally applicable treatment. ${ }^{[2]}$ Commonly cancer chemo- or radiotherapy is applied, that is usually associated with side effects due to a poor selectivity of most chemo- and radiotherapeutics toward cancer cells. ${ }^{[3]}$ To improve targeting, researchers have turned to nanotechnological approaches, using, for instance, lipid-based drug delivery systems such as micelles and liposomes. ${ }^{[4]}$

One type of nanoparticle of special interest for cancer therapy are iron oxide (containing) nanoparticles (IONPs). Magnetic IONPs indeed offer great therapeutic potential as, upon applying an alternating magnetic field, they can heat their environment (so called 'magnetic hyperthermia') ${ }^{[5]}$ When cancer cells are exposed to elevated temperatures (for instance $45{ }^{\circ} \mathrm{C}$ ) inactivation and eventually cell death may occur. In the groundbreaking work by Jordan et al. ${ }^{[6]}$ the ability of IONPs to induce elevated temperatures was clearly demonstrated. From then on, the exploitation of IONPs for cancer treatment by hyperthermia has gained substantial interest and clinical trials are currently being pursued in which the efficacy of magnetic hyperthermia on, for instance, recurrent glioblastoma multiforme patients is being evaluated. ${ }^{[7,8]}$ Also note that iron oxide cores are broken down within the body, ${ }^{[9]}$ resulting in free iron that can be readily metabolized by most cell types, rendering them biocompatible. ${ }^{[10]}$

Although IONPs may, after intravenous injection, be magnetically targeted to tumors to a certain extent, ${ }^{[11]}$ the local and precise delivery of IONPs into tumors remains a major challenge. Indeed, after intravenous injection most nanoparticles become rapidly cleared by the reticuloendothelial system which may necessitate the direct injection of IONPs in (accessible) tumors to allow magnetic hyperthermia. Furthermore, as even a single remaining cancer cell can lead to the recurrence of tumor formation, repeated applications of mild hyperthermia $\left(41-45^{\circ} \mathrm{C}\right.$, to minimize secondary effects on surrounding healthy tissues) in combination with other treatment modalities are highly preferred. It would be therefore highly advantageous if a material could be developed that would allow the repeated heating of the IONPs. When injecting dispersions of (free) IONPs, the uptake/adhesion of IONPs by/to tumor cells is likely to be crucial for a successful therapy. However, following the application 
of the alternating magnetic field, one can expect that such cell-associated IONPs will be released from the dying tumor cells and become endocytosed by surrounding healthy cells or migrating macrophages, hindering repeated magnetic heating. ${ }^{[8]}$

In order to further exploit the exciting possibilities of magnetic hyperthermia offered by IONPs, the present study aims to encapsulate IONPs in nanofibers with the final purpose to place them in the immediate vicinity of a tumor to capture metastatic cancer cells and to kill them through magnetic heating. Although these fibers would be larger in size and thereby not be suited for intravenous administration or targeted delivery to deeply seeded tumors in contrast to free IONPs, they may present an attractive alternative for local magnetic hyperthermia treatment of easily accessible tumors. The nanofibers are made through electrospinning; the ease and flexibility of the electrospinning process allows the design of polymeric fibers starting from either aqueous or organic solvent-based polymer solutions, with a high degree of control over the physical dimensions of the fibers. ${ }^{[12]}$ Compared to classical cast hydrogels, webs of electrospun fibers have a high surface to volume ratio and high porosity, ${ }^{[13]}$ that might be beneficial for (cancer) cell binding. Also, hydrogels only allow the encapsulation of relative small amounts of IONPs, ${ }^{[14]}$ while higher amounts of IONPs may become encapsulated in electrospun fibers, which is of interest as, for sufficient heating, relatively high amounts of IONPs are required. ${ }^{[14]}$ Clearly, once placed at the desired location, such IONPs containing fiber webs are expected to remain locally, keeping the IONPs in the surroundings of the tumor, thus allowing a repeated localized heating.

\section{Results and Discussion}

\subsection{Magnetic Electrospun Fiber Production and Characterization}

As Figure 1A (and Supporting Information (SI), Figure S1) shows, $50 \mathrm{~nm}$ diameter IONPs loaded polystyrene (PS) fibers were made through the use of an IONPs dispersion in tetrahydrofuran (THF); a PS solution (in dimethylformamide (DMF)/ THF (1/3)) was added to the IONPs dispersion and subsequently electrospun into fibers. During spinning, the organic solvent, that could be hazardous to cells, completely evaporates due to the high volatility of the solvent used. ${ }^{[15]}$ Prior to cell exposure, all fiber webs were also rinsed with distilled water for $15 \mathrm{~min}$ to remove any possible remnants of the organic solvents

D
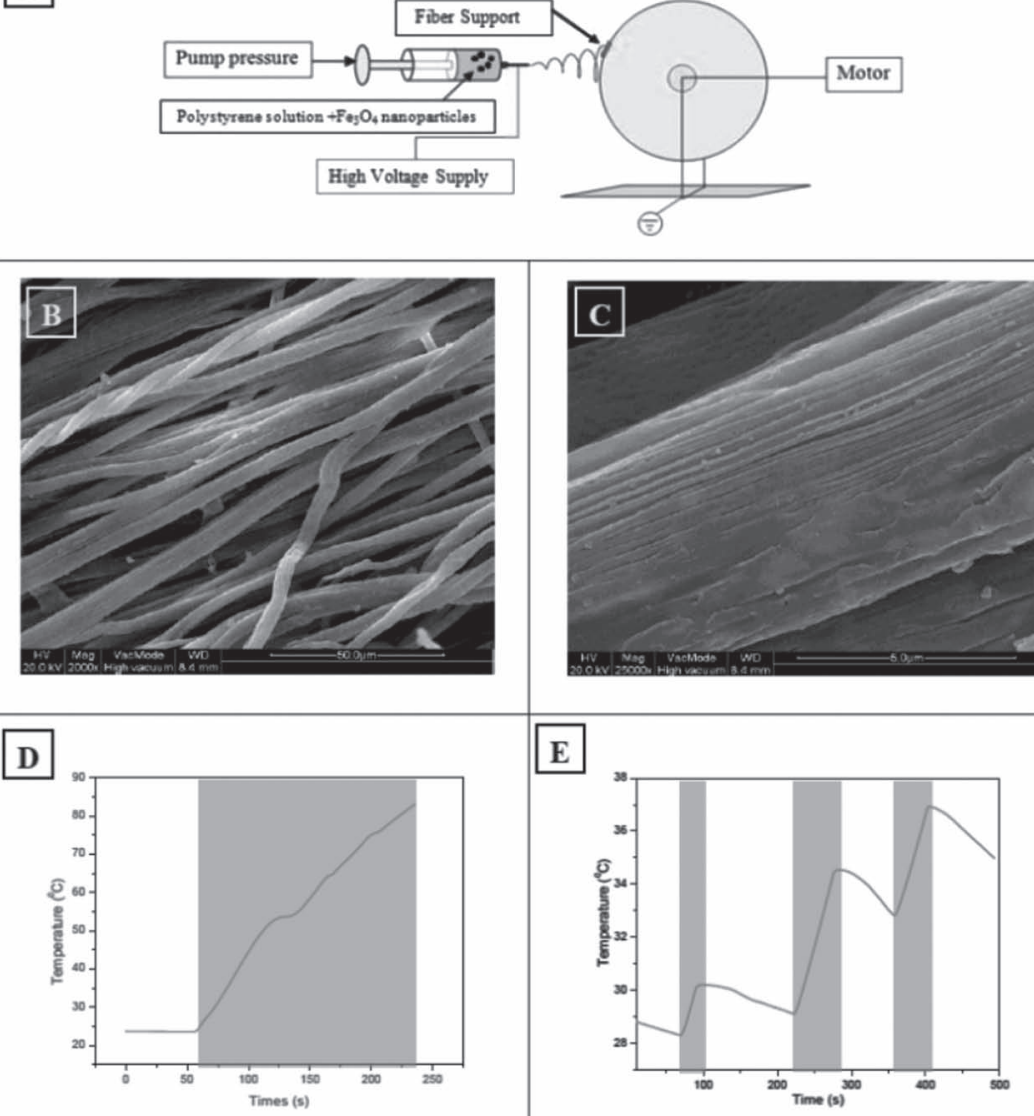

E

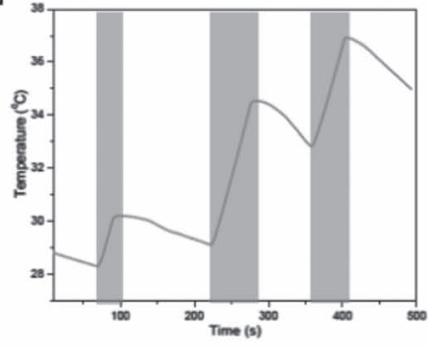

Figure 1. A) Schematic representation of the preparation of IONP-loaded PS fiber webs by electrospinning. B) and C) SEM images of electrospun fibers containing $20 \% 50 \mathrm{~nm}$ iron oxide nanoparticles. D) Temperature-time profile obtained upon heating PS-IONPs fibers (20\% IONPs) during which the magnetic field was on. E) Temperature-time profile obtained upon repeated heating (with a $27.1 \mathrm{kA} / \mathrm{m}$ and $232 \mathrm{kHz}$ alternating magnetic field; the grey zones indicate when the magnetic field was applied).

used. Scanning electron microscopy (SEM) data, as shown in Figure 1B, show a highly uniform diameter distribution of the electrospun PS fibers (see SI Figure S2; average fiber diameter $5 \mu \mathrm{m})$. PS solutions with various concentrations of IONPs were electrospun into fibers; SEM confirmed that fibers containing up to $20 \%$ of IONPs (weight IONPs/weight PS) did not display an aberrant morphology (Figure 1C). The images further show that the majority of IONPs becomes encapsulated inside fibers, and although several IONPs will likely be present on the fiber surface, no leakage of any particles was observed. This was confirmed by quantifying the amount of iron present in the fibers (dissolved by acid degradation) and the amount of iron in the surrounding medium after 2, 4, 8 and 14 days of fiber exposure to PBS, as measured using the colorimetric agent Tiron (See SI Table S1). Note that a higher loading of the PS fibers with IONPs was not feasible as this impaired the electrospinnability of the IONP-PS dispersions resulting in "beaded fibers" (due to the increased viscosity of the IONP-PS dispersions, see also previous work $^{[15]}$ ) (See SI Figure S3). Throughout this paper, fibers containing $20 \%$ of IONPs were used. 
In the next step, the heating capacity of webs made of the PS-IONPs fibers, upon applying an alternating magnetic field, was studied. Figure 1D shows that $282 \mathrm{mg}$ of IONP-containing PS fibers can heat $1 \mathrm{~mL}$ of water from $23^{\circ} \mathrm{C}$ to $83{ }^{\circ} \mathrm{C}$ in 180 seconds when an alternating magnetic field is applied $(27.1 \mathrm{kA} / \mathrm{m}, 232 \mathrm{kHz})$. These results reveal a powerful heating capacity of the fibers. The specific adsorption rate (SAR) of the PSIONPs fibers was subsequently calculated following Drake et al. ${ }^{[16]}$ For an alternating magnetic field of $700 \mathrm{kHz}$ and $22.1 \mathrm{kA} / \mathrm{m}$, an SAR of $84 \mathrm{~W}$ per gram PS-IONPs fibers was obtained, which is comparable to SAR values obtained for IONPs (of similar diameter) that range between 64.6 and $165 \mathrm{~W}$ per gram IONPs (when normalized to the magnetic field settings used in the current study). ${ }^{[17]}$ In general, magnetic field-induced heating of IONPs occurs through a combination of Brownian relaxation, Néel relaxation or hysteresis. ${ }^{[18]}$ As IONPs are strongly hydrophobic, causing them to aggregate in an aqueous environment, the precise underlying mechanism of heating by IONPS cannot be easily studied. It can however be suggested that as IONPs are firmly encapsulated within the electrospun PS fibers, their Brownian relaxation is likely very limited, whereas the relatively large size of the IONPs (50 nm diameter) will favor hysteresis over Néel relaxation as the main mechanism of magnetic energy dissipation. ${ }^{[19]}$ As previously mentioned, one of the key advantages of applying IONP loaded fiber webs somewhere in the body is the fact that the IONPs remain localized, hereby offering the ability to repeat the magnetic heating. Figure 1E shows that the IONPcontaining electrospun fibers definitely have this property as upon successive heating and cooling, the heating performance of the fiber webs has been well maintained (as indicated from the slope of the curves in the heating phases). Furthermore, iron was not detected in the surrounding media (See SI Table S2) indicating that the fibers remain intact and do not release any of the embedded IONPs upon repeated heating.

\subsection{Functionalization of Magnetic Electrospun Fibers to Enhance Cell Attachment}

The use of electrospun fibers for the encapsulation of IONPs has the additional advantage that fibers display a very high surface over volume ratio; this may enhance their interactions with e.g., surrounding cells and (partially) explains the considerable interest in the use of such fibers for tissue engineering purposes. ${ }^{[20]}$ Furthermore, the ease of chemical functionalization of the surface of the fibers may provide further opportunities. The primary application of the magnetically responsive electrospun fibers in this study lies in cancer therapy. Although the fibers can be surgically sutured near the tumor site, a biological surface which allows for close contact with the surrounding tissue would be preferred. Furthermore, by modifying the fiber surface, circulating cells such as metastatic cancer cells could also be bound to destroyed upon magnetic heating. For this purpose, the adhesion of cancer cells to the fibers is an important requirement. Figure 2 shows representative images of PSIONPs fibers with various surfaces that have been exposed to SKOV-3 ovarian cancer cells under continuous rotation to avoid cell sedimentation on top of the fiber webs. In most studies to date, electrospun fibers are typically placed on the bottom of tissue culture dishes after which a cell suspension is added. Cells will quickly start to sediment and thereby cover the fiber webs put at the bottom of the tissue culture dishes, resulting in high numbers of cell growing on top of the electrospun fibers. Using our approach, the continuous rotation avoids cell sedimentation and allows the study of the natural affinity of uncoated, PAH- and collagen-coated PS fibers for cell binding. Figure 2A shows that cell adhesion to "naked" (i.e., nonfunctionalized) PS-IONPs fibers is rather limited. Attaching sulfate groups on the PS-IONPs fibers did not improve the binding of cancer cells (Figure 2B), which could be expected as cell membranes show a net negative charge. However, coating the sulfated PS-IONPs fibers with poly(allylamine hydrochloride) (PAH), a weak cationic polyelectrolyte, and further applying collagen, an important component of the extracellular matrix that facilitates the adhesion of a wide range of cell types, ${ }^{[21]}$ on the surface of the fibers significantly improves the adhesion of the cells to the fibers. Interestingly, using a lactate dehydrogenase assay, no toxicity of the uncoated, PAH- or collagen-coated fibers to SKOV-3 cells was observed (See SI Figure S4).

\subsection{Effect of Water bath Heating on Fiber-Attached Cancer Cells}

Subsequently we aimed to analyze the effect of heating of the fibers on ovarian cancer cells attached to fibers. The samples were heated by the use of respectively a warm water bath (SI Figure S5, control experiments) and a magnetic field (Figure 3. Following heat exposure, the cells were stained with (a) calcein $\mathrm{AM}$, where the AM moiety is cleaved off by cellular esterases in living cells (resulting in a green fluorescent cytoplasm when cells are alive) and (b) ethidium homodimer, a membrane impermeable red dye that stains the nuclear region of cells with a damaged cell membrane. ${ }^{[22]}$ SI Figure S5 shows that incubation of the fiber-attached cells at $37{ }^{\circ} \mathrm{C}$ did not affect cell viability, as evidenced by the bright green fluorescence of the fiber-attached cells. Exposure of cells to $45{ }^{\circ} \mathrm{C}$ resulted in pronounced cell death as indicated by the decrease in green 


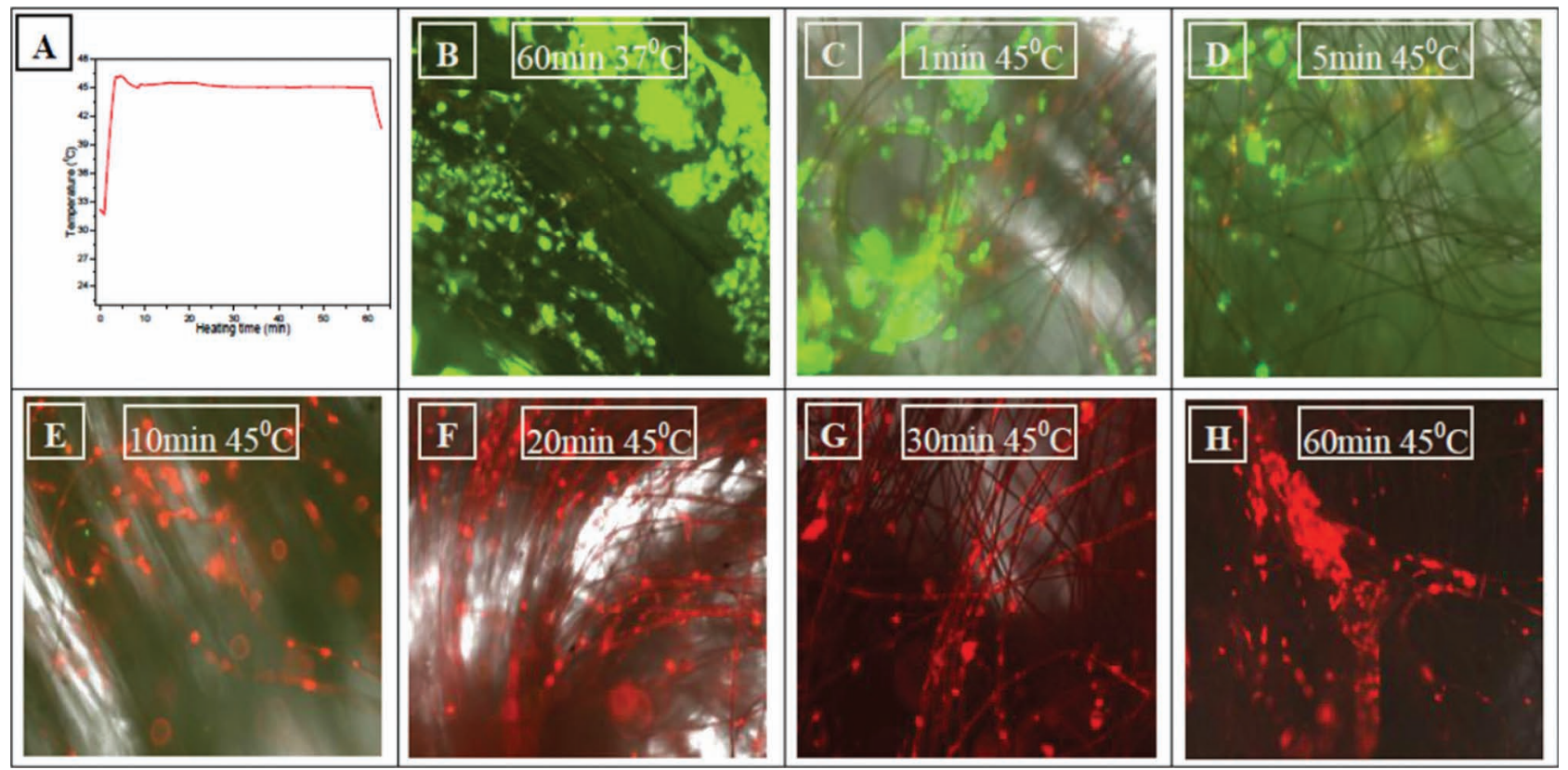

Figure 3. Viability of ovarian cancer cells bound on PS-IONP fibers heated by a AC magnetic field. A) Temperature-time profile obtained upon heating PS-IONP fibers (20\% IONPs) with a $15.8 \mathrm{kA} / \mathrm{m}$ and $232 \mathrm{kHz}$ AC magnetic field. B) The control sample, being cells kept in a $37^{\circ} \mathrm{C}$ water bath for 1 hour. C-H) PS-IONP fibers (20\% IONPs) with adsorbed ovarian cancer cells are heated to $45^{\circ} \mathrm{C}$ by an alternating magnetic field as shown in Figure $3 \mathrm{~A}$ for different durations (C:1 min, D:5min, E:10 min, F:20 min, G:30 min, H:60 min), showing all cells are dead after 10 min heating. Green: alive cells, red: dead cells. All pictures are overlays of a transmission image showing the fibers and a 2-color fluorescence image.

fluorescence of the cell cytoplasm and a higher number of cells showing only a red-colored nucleus $(22 \%$ and $61 \%$ cell death for 1 and $3 \mathrm{~h}$ exposure). As repeated heating and cooling of cells has been reported to result in more cell destruction, ${ }^{[23]}$ cells exposed to five cycles of heating (at $45^{\circ} \mathrm{C}$ ) and cooling $\left(37^{\circ} \mathrm{C}\right)$ were all killed (SI Figure S5E,F), which is significantly more than when compared to the continuous heating of the cells $\left(45^{\circ} \mathrm{C}\right)$. A similar observation was made by Wilhelm et al.[24] who applied an alternating magnetic field on prostate carcinoma cells labeled with dimercaptosuccinic acid (DMSA)-coated IONPs and observed $44 \%$ cell death after one hour of exposure, whereas $80 \%$ of the cells could be killed by a second exposure. A possible explanation for this observation is that a single exposure to elevated temperatures may induce protein denaturation to which the cell will respond by altering protein expression levels and, for instance, upregulating the expression of heat shock family proteins. If the cellular damage is too severe, the cells will die immediately, whereas many of the other cells can continue to live on, although weakened. Inducing rapid temperature changes by applying a second or third cycle of magnetic heating can then induce considerably more damage (the so-called "shock-effect") to the already weakened cells than maintaining the elevated temperature as cells have a strong tendency to adapt to a constant trigger.

\subsection{Effect of Magnetic Heating on Fiber-Attached Cancer Cells}

Next, the SKOV-3 cell loaded PS-IONP fibers were remotely heated by exposure to an alternating magnetic field. As the application of a magnetic field results in a rapid and continuous increase in temperature of the medium surrounding the fiber webs (see Figure 1D), the amplitude was continuously adjusted to quickly reach $45{ }^{\circ} \mathrm{C}$ and maintain this temperature for the duration of the experiment. Figure $3 \mathrm{~A}$ shows a representative temperature-time profile of the medium surrounding the magnetic fiber webs: upon applying the alternating magnetic field, in approximately two to three minutes the temperature rapidly increases to $45^{\circ} \mathrm{C}$ and can be steadily kept at $45^{\circ} \mathrm{C}$ for at least one hour (a maximal overshoot in the beginning of $2{ }^{\circ} \mathrm{C}$ at the most was observed). Figure 3B shows that "control" cells, being cells that were kept in a water bath at $37^{\circ} \mathrm{C}$ for one hour, did not show any distinct cell death. Exposure of the cell loaded PSIONP fibers to the magnetic field for 1 min already resulted in some cell death (Figure 3C; 14\% cell death), that was further pronounced when the field was applied for 5 min (Figure 3D; $24 \%$ cell death). When the webs were exposed to the magnetic field for 10 min (Figure 3E; 100\% cell death) or longer all cancer cells were killed (20 min: 3F; 30 min: 3G, 60 min: 3H; 100\% cell death), as shown by the lack of green fluorescence and the high number of red nuclei. The figures clearly show the association of the cancer cells to the collagen-coated fibers as all fluorescent stainings colocalize with the fibers. Importantly, the outspoken cell death at such short exposure times indicates a high cell killing efficiency of the magnetic fiber webs.

Currently, the application of magnetic hyperthermia mostly relies on the use of free "water-dispersible" IONPs, that can be injected intravenously after which they may reach the tumor and be endocytosed by the tumor cells. Although a lot of work has been done on IONP surface chemistry to improve tumor 
targeting, the majority of the particles are rapidly cleared from the bloodstream by the reticuloendothelial system ${ }^{[25]}$ and only a minor portion actually reaches the tumor, where most of the particles will be taken up by cancer cells at the periphery of the tumor while the inner tumor mass is reached to a lesser extent. ${ }^{[26]}$ To overcome this problem, most studies have focused on cationic IONPs that are directly injected into the tumor mass. ${ }^{[27]}$ This strategy is however limited to tumors that are readily accessible to the surgeon, such as skin tumors, and still suffers from the deleterious release and migration of the particles upon tumor cell death. Le Renard et al. ${ }^{[14]}$ therefore suggested to use polymeric formulations that gelate in situ when injected into intratumoral vascular and necrotic spaces. The encapsulation of the IONPs within the gel matrix greatly impedes IONP release and allows to apply multiple heating cycles, if needed. Unfortunately, the authors found that such hydrogel formulations are not well-suited for this purpose due to gelation problems at higher IONP concentrations. Organogel formulations seemed to be better suited but suffer from toxic side-effects due to the organic solvents. ${ }^{[14]}$ In the present work, electrospinning of IONPs dispersed in an (PS containing) organic solvent allows to obtain polymer matrices highly loaded with IONPs (up to 20\%) with only residual amounts of organic solvent.

Also, upon injection of 'water-dispersible' IONPs the amount of IONPs that will eventually be tumor-associated will not only be rather low but, especially, highly variable and unpredictable. The fiber webs described in this study, that can be (reproducibly) loaded with a well controlled amount of IONPs, may further overcome this problem and may thus offer a highly reproducible magnetic heating of cells. Magnetic electrospun fibers have been described previously, for a variety of magnetic particles such as magnetite, cobalt or Mn-Zn-Ni encapsulated in a variety of polymers. ${ }^{[28]}$ Where the principle of electrospinning remains similar, most of these previous studies focused primarily on the production and characterization of the magnetic fibers where direct biomedical applications of such magnetic electrospun fibers are only rarely reported. ${ }^{[29]}$ Here, fibers were further optimized for biomedical use by functionalizing the fiber surfaces. This allowed us to clearly demonstrate the importance of the fiber surface for high affinity cell binding and the possible use of coated fibers for cell binding applications. Furthermore, the magnetic properties of the electrospun fibers were clearly demonstrated in the magnetic hyperthermia experiments. The high loading capacity of the fibers was shown to be more than sufficient to induce high and rapid temperature increases when the fibers were exposed to an alternating magnetic field (Figure 1D, 1E) without any detectable loss of IONPs or decrease in heating capacity (Figure 1E). The heat produced was furthermore very effective at killing fiber-bound ovarian cancer cells (Figure 3), to a much greater extent than fiber-bound cells that were exposed to a water bath at the same temperature (Figure 3). This is likely explained by the close association of the cells to the fiber webs, where the local temperature may be somewhat higher than $45^{\circ} \mathrm{C}$ being the average temperature of the surrounding medium. Our results show that the magnetic fiber webs are very effective in destroying cells that are in close proximity of the fibers, whereas cells that are at some distance from the fibers will likely display the same behavior as the water bath heated cells in Figure 3B,D,E and therefore display much less toxicity. As the temperature of the fibers can easily be tuned by adjusting the amplitude and the frequency of the alternating magnetic field, the spatiotemporal temperature distribution upon heating the webs may be well controlled to achieve maximal tumor cell death while minimizing the effect of heating on the surrounding healthy cells. As the repeated application of magnetic hyperthermia might potentially affect the surrounding healthy tissue to a higher or lesser extent than free IONPs, more research in 3D tumor models is required to optimize the exact positioning and architecture of the fiber webs and the specifications of the alternating magnetic fields to be used in vivo in order to minimize any undesired side-effects.

Also note that the high iron oxide content of the magnetic fibers may allow to visualize the location of the fibers by means of Magnetic Resonance Imaging, providing a powerful tool to noninvasively study the long-term location of the fibers and correlate the correct application thereof with respect to the tumor. However, this possibility remains to be addressed in further in vivo studies as the presence of high local concentrations of IONPs and the hydrophobic PS fibers may result in severe imaging artifacts due to the significant alterations of the local magnetic field. Another interesting potential is that the magnetic electrospun fibers may be loaded with drugs as well;:[13] in analogy with already studied heat sensitive drug release systems such as, e.g., thermosensitive liposomes, ${ }^{[30]}$ the encapsulated therapeutic molecules could become released upon heating of the fibers. By electrospinning it is also well possible to design core-shell fibers through simultaneous spinning using two coaxial capillaries. ${ }^{[31]}$ An interesting approach could be, for instance, to produce fibers having antitumoral drugs encapsulated in a temperatureresponsive shell ${ }^{[32]}$ while the core contains the magnetic nanoparticles. Applying a magnetic field will then not only induce heat but may also trigger a local release of antitumor drugs.

In contrast to free IONPs that can be applied by means of intravenous administration, potentiating uptake of magnetic particles by deeply seeded tumors, the application of the magnetic fiber webs would primarily be limited to better accessible tumors. However, also tumors which are unresectable, such as pancreatic tumors, could be potential targets. Rather than performing complete surgery, surgeons often acquire biopsies using fine needles to confirm their original diagnosis. During this procedure, magnetic fiber webs could be implanted at the region where the biopsy is performed, making use of the fine needles already in place. Further note that antibodies attached to the surface of the fibers might enhance the adhesion of specific cells to the fibers. ${ }^{[33]}$ One interesting target protein for instance would be N-cadherin, that has been described to be a key marker for metastatic ovarian cancer cells and is of great importance in the cell motility. ${ }^{[34]}$ As metastatic ovarian cancer cells can freely travel through the peritoneal fluid, they can eventually widely distribute throughout the body. Applying a magnetic fiber web functionalized with anti-N cadherin antibodies in the peritoneum might be an interesting approach to capture and kill such cells through repeated heating that may lower the risk for metastasis. However, it should be first demonstrated whether such antibodies can withstand the elevated temperatures that arise when applying the magnetic field. 


\section{Conclusions}

The present work describes the incorporation of IONPs into electrospun PS fibers for the purpose of developing novel mediators for magnetic hyperthermia as an anti-cancer strategy. It was demonstrated that IONPs can be encapsulated in PS fibers at concentrations of up to $20 \%$ without any effect on fiber morphology. Furthermore, the magnetic properties of the IONPcontaining fibers resulted in an efficient heating capacity when exposed to an alternating magnetic field. Also, multiple heating and cooling cycles can easily be applied, without any loss of heating capacity or leakage of the encapsulated IONPs, making repeated heating possible which is in sharp contrast to the free IONPs that are currently studied in clinical trials. It is further shown that magnetic fibers can be easily be functionalized with collagen that allows cell binding. Upon exposure of web-bound cells to $45^{\circ} \mathrm{C}$, either by a warm water bath or by an alternating magnetic field, the temperature-dependent killing of ovarian cancer cells was demonstrated. Magnetic field induced hyperthermia seemed much more efficient in cell killing than water bath heating as complete cell death was observed after exposing the fibers for $10 \mathrm{~min}$ to the magnetic field.

\section{Experimental Section}

Materials: dimethylformamide (DMF), tetrahydrofuran (THF), 4,5-Dihydroxy-1,3benzenedisulfonic acid disodium salt monohydrate (Tiron) and $50 \mathrm{~nm}$ iron oxide $\left(\mathrm{Fe}_{3} \mathrm{O}_{4}\right)$ nanopowder $(<50 \mathrm{~nm})$ (CAS:13176-9) were purchased from Aldrich (Steinheim, Germany). Poly(allylamine hydrochloride) (PAH) was purchased from Sigma-Aldrich (Bornem, Belgium). Polystyrene (PS, MW $100000 \mathrm{~g} / \mathrm{mol}$, lot number 10099118) was purchased from Alfa Aesar (Karlsruhe, Germany). The mammalian cell Live/Dead viability kit and rat tail collagen-1 were purchased from Invitrogen (Merelbeke, Belgium).

Cell Culture: SKOV-3 cells were cultured in Iscove's Modified Dulbecco's Medium (IMDM) containing 10\% fetal calf serum (FCS), $2 \mathrm{~mm}$ L-Glutamine, $100 \mu \mathrm{g} \mathrm{mL}^{-1}$ streptomycin, $100 \mathrm{U} \mathrm{mL}^{-1}$ penicillin (all from Gibco-Invitrogen, Merelbeke, Belgium).

Electrospinning of $\mathrm{Fe}_{3} \mathrm{O}_{4} \mathrm{NPs}$ Loaded Polystyrene Fibers: For dispersing iron oxide $\left(\mathrm{Fe}_{3} \mathrm{O}_{4}\right)$ nanopowder in $\mathrm{THF}, 0.6 \mathrm{~g}$ nanopowder was added into $9 \mathrm{~mL}$ THF, after which the dispersion was exposed to ultrasound (Bransonic 2510E-MTH, Input $240 \mathrm{~W}$, output $100 \mathrm{~W}$ ) for 24 hours. A PS solution (in dimethylformamide (DMF)/THF; 1/3) was added to the IONPs dispersion and subsequently electrospun into fibers. A high voltage power supply (up to $40 \mathrm{kv}$ ), a syringe, a flat-tip needle and a grounded collector were used in the electrospinning device. Typically, electrospinning of a $5 \mathrm{~mL} \mathrm{PS} / \mathrm{IONPs}$ dispersion was conducted at a $2 \mathrm{~mL} \mathrm{~h}^{-1}$ feeding rate using a syringe pump (Prosense B.V. NE 300 USA). The applied voltage was kept at $10 \mathrm{kV}$. The IONPs loaded fibers were deposited on the grounded rotating collector, rotating at $1500 \mathrm{rpm}$, that was placed $15 \mathrm{~cm}$ beneath the needle tip.

SEM: A small amount of fiber webs that were made as described above, under identical conditions as those fibers used for biological studies, was deposited onto a silicon wafer and dried under a nitrogen stream, followed by sputtering with gold. SEM images were recorded with an FEI. Quanta 200 FEG scanning electron microscope operated at an acceleration voltage of $15 \mathrm{kV}$.

Surface Modification of the Fibers: Electrospun magnetic PS fibers $(10 \mathrm{mg})$ were immersed into a concentrated sulfuric acid solution $(9.8 \mathrm{M}, 10 \mathrm{~mL})$ and stirred for $3 \mathrm{~min}$ to facilitate sulfonation of the fiber surface. The thus obtained negatively charged fibers were removed from the acid solution and were subsequently washed with distilled water until the solution $\mathrm{pH}$ was approximately neutral. Sulfonated PS fibers (approximately $10 \mathrm{mg}$ ) were immersed into an aqueous solution of the polyelectrolyte PAH $\left(2 \mathrm{mg} \mathrm{mL}^{-1}, 0.5 \mathrm{M} \mathrm{NaCl}, 5 \mathrm{~mL}\right)$ for $15 \mathrm{~min}$ and then rinsed 3 times with distilled water. Finally, the PAH coated fibers were immersed in a solution of collagen $\left(0.45 \mathrm{mg} \mathrm{mL}^{-1}\right.$ in PBS) for $15 \mathrm{~min}$ and rinsed for $3 \mathrm{~min}$ in distilled water.

Adsorption of Ovarian Cancer Cells to Fiber Webs: Neutral, negatively charged and collagen coated magnetic fiber webs were exposed to ovarian cancer cells $\left(100,000\right.$ cells well $\left.^{-1}\right)$ dispersed in cell medium (in a falcon tube), applied on a shaker in a humidified atmosphere at $37{ }^{\circ} \mathrm{C}$ and $5 \% \mathrm{CO}_{2}$. After 2 hours, all samples were transferred to six well plates and stored in the incubator overnight. Afterwards all samples were stained using DAPI nuclear stain $\left(0.5 \mu \mathrm{g} \mathrm{mL}^{-1}\right)$ for $5 \mathrm{~min}$ at room temperature followed by 3 times washing with PBS.

Determination of Fiber Toxicity: Uncoated, $\mathrm{PAH}$ - and collagen-coated magnetic fiber webs at different concentrations (50, 100, 200, 281, $350 \mathrm{mg}$ fiber webs $\mathrm{mL}^{-1}$ ) were exposed to SKOV-3 cells as described above $\left(100,000\right.$ cells well $\left.{ }^{-1}\right)$. After $2 \mathrm{~h}$, the tubes were kept still for $10 \mathrm{~min}$ to allow cell sedimentation and $50 \mu \mathrm{L}$ of supernatant was taken and transferred to a well of a 96-well plate. The effect of the fibers on cell viability was then assessed by measuring the amount of lactate dehydrogenase present in the surrounding medium by performing the LDH assay (Promega, Leiden, The Netherlands) according to the manufacturer's instructions. Data are expressed relative to that of control cells treated identically with omission of magnetic fibers. Negative controls were also added by treating the cells with $0.1 \%$ Triton X-100 for 10 min prior to sample collection.

Heating of the Magnetic Fibers: To screen the heating capacity of the fibers, $281 \mathrm{mg}$ of magnetic PS fiber webs (containing 20\% of IONPs (weight IONPs/weight PS) was dispersed in a falcon tube containing $1 \mathrm{~mL}$ distilled water. The falcon tube was then placed in the center of the coil of a magnetic heating device (High Frequency generator HTG10000/HTG 0.45N; Linn High Therm Gmbh, Eschenfelden, Germany, equipped with a 3 windings-counting coil of $47 \mathrm{~mm}$ height and $84 \mathrm{~mm}$ aperture). For heating, an alternating magnetic field was applied (750 Amp and $232 \mathrm{KHz}$ ). The sample temperature was then measured using a wire-type electric thermocouple (submerged in the heating medium of the falcon tube) that is coupled to the heating device (Linn High Therm $\mathrm{GmbH}$, Eschenfelden, Germany). The iron concentration in the medium surrounding the magnetic fibers was measured as described previously, ${ }^{[35]}$ based on a spectrophotometric determination of $\mathrm{Fe}^{3+}$-responsive coloured Tiron complexes as indicator dyes.

Determination of Iron Content of Fibers and Fiber Surrounding Medium: The iron content of magnetic fibers was measured using Tiron. To this end, a sample of magnetic fibers $(10 \mathrm{mg})$ was dispersed in $200 \mu \mathrm{L}$ of a mixture of concentrated hydrochloric acid and nitric acid (3/1 volume ratio) and left to digest for $48 \mathrm{~h}$ at $37{ }^{\circ} \mathrm{C}$. Then, $9.8 \mathrm{~mL}$ of distilled water was added, resulting in a total dilution of $50 \times$ and $500 \mu \mathrm{L}$ of this dilution was taken. Next, $600 \mu \mathrm{L}$ of a diluted Tiron solution was added $(100 \mu \mathrm{L}$ of $0.25 \mathrm{~m}$ Tiron $+500 \mu \mathrm{L} \mathrm{KOH} 4 \mathrm{~N})$ followed by the addition of $1 \mathrm{~mL}$ of phosphate buffer, $0.2 \mathrm{M}, \mathrm{pH} 9.5$ after which the absorbance is measured at $480 \mathrm{~nm}$, as described previously. ${ }^{[35]}$ For detection of iron in the surrounding medium after long-term exposure, $281 \mathrm{mg}$ of fibers were dispersed in $1 \mathrm{~mL}$ of PBS. After 2, 4, 8 and 14 days, $400 \mu \mathrm{L}$ of this medium was taken and replaced by $400 \mu \mathrm{L}$ of fresh PBS. The iron content in the $400 \mu \mathrm{L}$ of sample was measured by adding $0.24 \mathrm{~mL}$ concentrated $\mathrm{HCl}$ and $0.08 \mathrm{~mL}$ concentrated $\mathrm{HNO}_{3}$ and these samples were allowed to digest for $48 \mathrm{~h}$ at $37^{\circ} \mathrm{C}$. Then, $0.68 \mathrm{~mL}$ of distilled water was added, $500 \mu \mathrm{L}$ of this dispersion and treated similarly as described above. For detection of iron in the surrounding medium after magnetic heating, $281 \mathrm{mg}$ of magnetic fibers were subjected to magnetic heating as described in the above section. To this end, the fibers were submerged in $1 \mathrm{~mL}$ of distilled water. After 1, 2, 3 or 4 rounds of magnetic heating, $400 \mu \mathrm{L}$ of the medium was taken and replaced by $400 \mu \mathrm{L}$ of fresh distilled water. To the $400 \mu \mathrm{L}$ sample, $0.24 \mathrm{~mL}$ of concentrated $\mathrm{HCl}$ and $0.08 \mathrm{~mL}$ of concentrated $\mathrm{HNO}_{3}$ were added after which the samples were treated identically as described above. All iron determination experiments were performed in triplicate.

Determination of Cancer Cell Viability: The viability of cancer cells bound to the magnetic fibers was measured after heating them through 
respectively the use of a warm water bath or exposure to an alternating magnetic field.

Magnetic fiber webs, loaded with ovarian cancer cells as described above, were put in falcon tubes containing $1 \mathrm{~mL}$ of full cell medium and placed in a temperature controlled water bath at either $37^{\circ} \mathrm{C}$ or $45^{\circ} \mathrm{C}$ for 1 or $3 \mathrm{~h}$. In order to investigate the effect of repeated heating, one sample was exposed to five subsequent heating and cooling cycles (switching between 45 and $37^{\circ} \mathrm{C}$, respectively) for a total duration of $3 \mathrm{~h}$ (the time-dependent temperature profile can be seen in SI Figure S5F).

For heating by an external magnetic field, magnetic fiber web samples (each of them was $73 \mathrm{mg}$ ) were loaded with ovarian cancer cells as described above and transferred into falcon tubes after which $1 \mathrm{~mL}$ of full cell medium was added. For control samples, the tubes were immersed into a $37^{\circ} \mathrm{C}$ water bath for $1 \mathrm{~h}$. The remaining samples (identical weight of fibers) were heated to $45{ }^{\circ} \mathrm{C}$ by applying an alternating magnetic field (350 Amp and $232 \mathrm{KHz}$ initially, then the amplitude and frequency were adjusted in order to keep $45^{\circ} \mathrm{C}$; see Figure $3 \mathrm{~A}$ ) for different times ( $1 \mathrm{~min}, 5 \mathrm{~min}, 10 \mathrm{~min}, 20 \mathrm{~min}, 30 \mathrm{~min}$ and $60 \mathrm{~min}$ )

After heating, all samples were stained using the live/dead cell viability kit according to the manufacturer's protocols. In short, the cell-covered fibers were collected from the tubes and placed in cell culture dishes after which the cells were immediately inducbated with calcein AM $(4 \mu \mathrm{M})$ and ethidium homodimer $(2 \mu \mathrm{M})$ for $45 \mathrm{~min}$, followed by washing twice with PBS, fixation with $2 \%$ paraformaldehyde for $15 \mathrm{~min}$ at ambient temperature and another 2 washes with PBS to remove the fixative. The samples were then viewed using a Nikon Te2000 (Nikon Belux, Brussels, Belgium) fluorescence microscope. Quantitative data regarding cell viability were obtained by counting the number of red (dead) cells for at least 300 cells per condition and expressed as the number of dead cells relative to the total number of cells (red and green).

\section{Supporting Information}

Supporting Information is available from the Wiley Online Library or from the author.

\section{Acknowledgements}

C.H. and S.J.S. contributed equally to this work. S.J.S. is a post-doctoral fellow from the FWO-Vlaanderen. Financial support from the Ghent University (BOF) is acknowledged with gratitude.

Received: September 13, 2011

Revised: January 17, 2012

Published online: March 16, 2012

[1] a) T. Sun, N. Aceto, K. L. Meerbrey, J. D. Kessler, C. Zhou, I. Migliaccio, D. X. Nguyen, N. N. Pavlova, M. Botero, J. Huang, R. J. Bernardi, E. Schmitt, G. Hu, M. Z. Li, N. Dephoure, S. P. Gygi, M. Rao, C. J. Creighton, S. G. Hilsenbeck, C. A. Shaw, D. Muzny, R. A. Gibbs, D. A. Wheeler, C. K. Osborne, R. Schiff, M. Bentires-Alj, S. J. Elledge, T. F. Westbrook, Cell 2011, 144, 703; b) H. Han, X. L. Li, BMC Bioinformatics 2011, 12 Suppl 1, S7; c) V. Trevino, M. G. Tadesse M. Vannucci, F. Al-Shahrour, P. Antczak, S. Durant, A. Bikfalvi, J. Dopazo, M. J. Campbell, F. Falciani, PLoS One 2011, 6, e16492.

[2] Y. Dong, W. K. K. Wu, C. W. Wu, J. J. Y. Sung, J. Yu, S. S. M. Ng, Brit. J. Cancer 2011, 104, 893.

[3] J. H. Maeng, D. H. Lee, K. H. Jung, Y. H. Bae, I. S. Park, S. Jeong, Y. S. Jeon, C. K. Shim, W. Kim, J. Kim, J. Lee, Y. M. Lee, J. H. Kim, W. H. Kim, S. S. Hong, Biomaterials 2010, 31, 4995.

[4] J. L. Arias, B. Clares, M. E. Morales, V. Gallardo, M. A. Ruiz, Curr. Drug Targets 2011.
[5] a) B. Chen, W. Wu, X. Wang, Curr. Cancer Drug Targets 2011, 11, 184; b) M. M. Yallapu, S. F. Othman, E. T. Curtis, B. K. Gupta, M. Jaggi, S. C. Chauhan, Biomaterials 2011, 32, 1890.

[6] A. Jordan, P. Wust, H. Fahling, W. John, A. Hinz, R. Felix, Int. J. Hyperthermia 1993, 9, 51.

[7] a) E. Duguet, S. Vasseur, S. Mornet, J. M. Devoisselle, Nanomedicine (London, U.K.) 2006, 1, 157; b) A. Jordan, Int. J. Hyperthermia 2009, 25, 512 .

[8] F. K. van Landeghem, K. Maier-Hauff, A. Jordan, K. T. Hoffmann, U. Gneveckow, R. Scholz, B. Thiesen, W. Bruck, A. von Deimling, Biomaterials 2009, 30, 52.

[9] K. Briley-Saebo, A. Bjornerud, D. Grant, H. Ahlstrom, T. Berg, G. M. Kindberg, Cell Tissue Res. 2004, 316, 315.

[10] a) S. J. Soenen, U. Himmelreich, N. Nuytten, T. R. Pisanic, 2nd A. Ferrari, M. De Cuyper, Small 2010, 6, 2136; b) M. Levy, N. Luciani, D. Alloyeau, D. Elgrabli, V. Deveaux, C. Pechoux, S. Chat, G. Wang, N. Vats, F. Gendron, C. Factor, S. Lotersztajn, A. Luciani, C. Wilhelm, F. Gazeau, Biomaterials 2011, 32, 3988.

[11] J. P. Fortin-Ripoche, M. S. Martina, F. Gazeau, C. Menager C. Wilhelm, J. C. Bacri, S. Lesieur, O. Clement, Radiology 2006, 239, 415.

[12] T. J. Sill, H. A. von Recum, Biomaterials 2008, 29, 1989.

[13] C. Huang, S. J. Soenen, J. Rejman, B. Lucas, K. Braeckmans, J. Demeester, S. C. De Smedt, Chem. Soc. Rev. 2011, 40, 2417.

[14] P. E. Le Renard, O. Jordan, A. Faes, A. Petri-Fink, H. Hofmann, D. Rufenacht, F. Bosman, F. Buchegger, E. Doelker, Biomaterials 2010, 31, 691.

[15] a) J. Shawon, C. Sung, J. Mater. Sci. 2004, 39, 4605; b) G. Gururajan, C. B. Giller, C. M. Snively, D. B. Chase, J. F. Rabolt, Appl. Spectroscopy 2011, 65, 858

[16] P. Drake, H. J. Cho, P. S. Shih, C. H. Kao, K. F. Lee, C. H. Kuo, X. Z. Lin, Y. J. Lin, J. Mater. Chem. 2007, 17, 4914

[17] C. L. Dennis, A. J. Jackson, J. A. Borchers, R. Ivkov, A. R. Foreman, P. J. Hoopes, R. Strawbridge, Z. Pierce, E. Goerntiz, J. W. Lau, C. Gruettner, J. Phys. D Appl. Phys. 2008, 41

[18] S. Mornet, S. Vasseur, F. Grasset, E. Duguet, J. Mater. Chem. 2004, 14, 2161.

[19] J. P. Fortin, C. Wilhelm, J. Servais, C. Menager, J. C. Bacri, F. Gazeau, J. Am. Chem. Soc. 2007, 129, 2628.

[20] J. Lannutti, D. Reneker, T. Ma, D. Tomasko, D. F. Farson, Mat. Sci. Eng. C-Bio. S. 2007, 27, 504

[21] J. Jokinen, E. Dadu, P. Nykvist, J. Kapyla, D. J. White, J. Ivaska, P. Vehvilainen, H. Reunanen, H. Larjava, L. Hakkinen, J. Heino, J. Biol. Chem. 2004, 279, 31956.

[22] S. J. Soenen, M. De Cuyper, Contrast Media Mol. Imaging 2011, 6, 153.

[23] N. Kawai, A. Ito, Y. Nakahara, H. Honda, T. Kobayashi, M. Futakuchi, T. Shirai, K. Tozawa, K. Kohri, Prostate 2006, 66, 718.

[24] C. Wilhelm, J. P. Fortin, F. Gazeau, J. Nanosci. Nanotechnol. 2007, 7 , 2933.

[25] a) T. K. Jain, M. K. Reddy, M. A. Morales, D. L. Leslie-Pelecky, V. Labhasetwar, Mol. Pharm. 2008, 5, 316; b) C. G. Hadjipanayis, R. Machaidze, M. Kaluzova, L. Y. Wang, A. J. Schuette, H. W. Chen, X. Y. Wu, H. Mao, Cancer Res. 2010, 70, 6303.

[26] L. L. Yang, X. H. Peng, Y. A. Wang, X. X. Wang, Z. H. Cao, C. C. Ni, P. Karna, X. J. Zhang, W. C. Wood, X. H. Gao, S. M. Nie, H. Mao, Clin. Cancer Res. 2009, 15, 4722

[27] S. J. Soenen, M. Hodenius, M. De Cuyper, Nanomedicine (London, U.K.). 2009, 4, 177.

[28] a) M. Wang, H. Singh, T. A. Hatton, G. C. Ruttledge, Polymer 2004, 45, 5505; b) P. Gupta, R. Asmatulu, R. Claus, G. Wilkes, J. Appl. Polym. Sci. 2006, 100, 4935; c) M. Graeser, M. Bognitzki, W. Massa, C. Pietzonka, A. Greiner, J. H. Wendorff, Adv. Mater. 2007, 19, 4244. 
[29] O. Kriha, M. Becker, M. Lehmann, D. Kriha, J. Krieglstein, M. Yosef, S. Schlecht, R. B. Wehrspohn, J. H. Wendorff, A. Greiner, Adv. Mater. 2007, 19, 2483.

[30] M. de Smet, E. Heijman, S. Langereis, N. M. Hijnen, H. Grull, J. Controlled Release 2011, 150, 102

[31] D. Li, Y. N. Xia, Adv. Mater. 2004, 16, 1151.

[32] J. Y. Ying, N. T. Zaman, Y. Y. Yang, Nano Today 2010, 5, 9.
[33] a) P. H. Tsou, C. K. Chou, S. Saldana, M. C. Hung, J. Kameoka, Nanotechnology 2008, 19, 445714; b) J. Bockelmann, K. Klinkhammer, A. von Holst, N. Seiler, A. Faissner, G. A. Brook, D. Klee, J. Mey, Tissue Eng. Part A 2011, 17, 475.

[34] M. P. Ponnusamy, I. Lakshmanan, M. Jain, S. Das, S. Chakraborty, P. Dey, S. K. Batra, Oncogene 2010, 29, 5741.

[35] M. De Cuyper, S. J. Soenen, Methods Mol. Biol. 2010, 605, 97. 